\title{
On the steady-state drop size distribution in stirred vessels. Part I: effect of dispersed phase viscosity
}

DOI:

10.1002/aic.16171

\section{Document Version}

Accepted author manuscript

Link to publication record in Manchester Research Explorer

\section{Citation for published version (APA):}

Carrillo De Hert, S., \& Rodgers, T. (2018). On the steady-state drop size distribution in stirred vessels. Part I: effect of dispersed phase viscosity. American Institution of Chemical Engineers Journal, 64(9).

https://doi.org/10.1002/aic.16171

\section{Published in:}

American Institution of Chemical Engineers Journal

\section{Citing this paper}

Please note that where the full-text provided on Manchester Research Explorer is the Author Accepted Manuscript or Proof version this may differ from the final Published version. If citing, it is advised that you check and use the publisher's definitive version.

\section{General rights}

Copyright and moral rights for the publications made accessible in the Research Explorer are retained by the authors and/or other copyright owners and it is a condition of accessing publications that users recognise and abide by the legal requirements associated with these rights.

\section{Takedown policy}

If you believe that this document breaches copyright please refer to the University of Manchester's Takedown Procedures [http://man.ac.uk/04Y6Bo] or contact uml.scholarlycommunications@manchester.ac.uk providing relevant details, so we can investigate your claim.

\section{OPEN ACCESS}




\title{
On the steady-state drop size distribution in stirred vessels. Part I: effect of dispersed phase viscosity
}

\author{
Sergio Carrillo De Hert, Thomas L. Rodgers* \\ School of Chemical Engineering and Analytical Science, The University of Manchester, \\ Manchester M13 9PL, UK
}

\begin{abstract}
Previous studies on emulsification have used the maximum drop size $\left(d_{\max }\right)$ or Sauter mean diameter $\left(\bar{d}_{32}\right)$ to investigate the effect of viscosity on the drop size distribution (DSD), however these parameters fall short for highly polydispersed emulsions. In this investigation (Part I) we studied the steady-state DSD of dilute emulsions using of silicon oils with viscosities varying across 6 orders of magnitude at different stirring speeds. Different emulsification regimes were identified; our modelling and analysis is centred on the intermediate viscosity range where interfacial cohesive stresses can be considered negligible and drop size increases with viscosity. The bimodal frequency distributions by volume were well described using two log-normal density functions. In Part $\mathrm{II}^{1}$ we expanded this study by using other continuous phases of different viscosity while keeping the Power number constant, thus examining the effects of viscosity ratio.
\end{abstract}

Keywords: Emulsification, Viscosity, Droplet size distribution, Stirred vessel, Drop breakup

\section{Introduction}

\footnotetext{
${ }^{*}$ Corresponding author: +44 (0)161 3068849

Email addresses: sergio.carrillodehert@manchester.ac.uk (Sergio Carrillo De Hert), tom.rodgers@manchester.ac.uk (Thomas L. Rodgers )
} 
bility, and interfacial area. The DSD of emulsified products through mechan6 ical mixing results from the breakup and coalescence of droplets. The latter 7 becomes negligible for dilute emulsions and allows isolation of the break-up 8 mechanism for its study.

Due to the complexity of turbulent fields a full theoretical description of describe the breakup process.

$$
\begin{aligned}
\mathrm{We}_{\mathrm{d}} & =\frac{\tau d_{\text {max }}}{\sigma} \\
\mathrm{Vi}_{\mathrm{H}} & =\frac{\mu_{d}}{\sqrt{\rho_{d} \sigma d_{\max }}}
\end{aligned}
$$

${ }_{17}$ Where $\tau$ is the stress experienced by the drop of diameter $d_{\text {max }} ; \sigma$ is the 18 interfacial tension in-between the dispersed and continuous phase, and $\mu_{d}$ number $\left(\mathrm{We}_{\mathrm{crit}}\right)$ number which is a function of $\mathrm{Vi}_{\mathrm{H}}$.

$$
\mathrm{We}_{\mathrm{crit}}=C_{1}\left[1-\psi\left(\mathrm{Vi}_{\mathrm{H}}\right)\right]
$$

22 It has been theorized that for droplets larger than the Kolmogorov length 
scale $\eta$ (for isotropic homogeneous turbulence) the stress $\tau$ experienced by a drop is due to the kinetic energy fluctuations, this is known as the turbulent inertia regime. Kolmogorov's length scale and the stress due to the kinetic energy fluctuations are given by ${ }^{2,3}$

$$
\begin{aligned}
& \eta=\left(\frac{\mu_{c}}{\rho_{c}}\right)^{\frac{3}{4}} \epsilon^{-\frac{1}{4}} \\
& \tau=C_{2} \rho_{c}\left(\epsilon d_{\max }\right)^{\frac{2}{3}}
\end{aligned}
$$

Where $\mu_{c}$ and $\rho_{c}$ are the viscosity and density of the continuous phase. For inviscid dispersed phases $\left(\mathrm{Vi}_{\mathrm{H}} \rightarrow 0\right)$ Equations 1,3 and 5 yield $d_{\max }=$ $C_{3}\left(\rho_{c} / \sigma\right)^{-3 / 5} \epsilon^{-2 / 5}$. Where $\epsilon$ is the energy dissipation rate per unit mass, which value depends on the location in the vessel. Authors like Zhou and Kresta $^{4}$ have suggested that the the equilibrium drop size is determined by the maximum energy dissipation rate $\epsilon_{\max }$ which is located in the impeller vicinity. There is much discrepancy on how to estimate $\epsilon_{\max }$ as it depends on the method and assumptions used for its estimation ${ }^{5}$. One of the scaling parameters used in literature is the $\epsilon_{\max } / \bar{\epsilon}$ ratio, where $\bar{\epsilon}$ is the mean dissipation rate and can be obtained from power draw $P$ measurements

$$
\bar{\epsilon}=\frac{P}{\rho_{c} V}
$$

Where $V$ is the volume of the vessel. For fully developed turbulence in a stirred vessel with a stirrer diameter $D$ rotating at a speed $N$ the dimensionless Power number $\left(\mathrm{Po}=P \rho_{c}^{-1} N^{-3} D^{-5}\right)$ becomes constant. Rushton et al. ${ }^{6}$ determined that $\bar{\epsilon}=C_{4} N^{3} D^{2}$. Combining Equations 1, 3 and 5 Shinnar and 
41

Church ${ }^{7}$ concluded that for inviscid, diluted droplets larger than $\eta$

$$
\frac{d_{\max }}{D}=C_{5}\left(\frac{\rho_{c} N^{2} D^{3}}{\sigma}\right)^{-\frac{3}{5}}=C_{5} \mathrm{We}_{\mathrm{S}}^{-\frac{3}{5}}
$$

42 Note that the Weber number defined above is based on the stirrer and not 43 on the stress experienced by the droplet $\left(\mathrm{We}_{\mathrm{S}}=\rho_{c} N^{2} D^{3} \sigma^{-1}\right)$.

${ }_{44}$ Sprow $^{8}$ proposed that the average drop sizes $\bar{d}_{p q}$ are proportional to the 45 maximum diameter.

$$
\bar{d}_{p q}=C_{6} d_{\max }
$$

${ }_{46}$ Where $\bar{d}_{p q}$ is

$$
\bar{d}_{p q}=\left[\frac{\int_{0}^{\infty} f_{n}\left(d_{i}\right) d_{i}^{p} \mathrm{~d} d_{i}}{\int_{0}^{\infty} f_{n}\left(d_{i}\right) d_{i}^{q} \mathrm{~d} d_{i}}\right]^{\frac{1}{p-q}}
$$

47 For $p=3$ and $q=2$ the Sauter mean diameter $\bar{d}_{32}$ can be obtained. The ${ }_{48} \bar{d}_{32}$ is specially useful as it links the interfacial area to its volume through ${ }_{49} a_{v}=6 \phi / \bar{d}_{32}$. Where $a_{v}$ is the interfacial area and $\phi$ the emulsion's volume 50 fraction.

${ }_{51} \quad$ Equation 8 made $d_{\max }$ and $\bar{d}_{32}$ interchangable and has been widely used ${ }_{52}$ but several values for $C_{6}$ have been reported in literature. Nishikawa et al. ${ }^{9}$ 53 found $C_{6}=0.45$ and Calabrese et al. ${ }^{10}$ found $C_{6} \approx 0.6$ for moderate viscous 54 oils and $C_{6} \approx 0.5$ for highly viscous due to the broadening of the DSD as ${ }_{55} \mu_{d}$ increases. Li et al. ${ }^{11}$ obtained bimodal DSD using a rotor-stator mixer 56 and found $C_{6}=0.16$. Liu and $\mathrm{Li}^{12}$ emulsified four crude oils with different 57 viscosity using a batch rotor-stator mixer as they took samples at different 58 time intervals. They obtained bimodal DSD and found that $C_{6}$ was inde- 
pendent of time but that $C_{6}$ decreased as $\mu_{d}$ increased and the distribution broadened. The aforementioned studies suggest that Equation 8 should be used with caution if a mechanistic model based on $d_{\max }$ is applied to viscid materials.

Other mechanistic and empirical models apart from Equation 7 have been suggested and many have been summarized by Singh et al. ${ }^{13}$.

The three paper study by Calabrese et. al. ${ }^{10,14,15}$ has been the most important to describe the effect of $\mu_{d}$ and $\sigma$ for viscid dispersed phases. For their mechanistic model Calabrese et al. ${ }^{10}$ and Wang and Calabrese ${ }^{14}$ balanced the disrupting and the surface and viscous cohesive energies

$$
\frac{\bar{d}_{32}}{D}=C_{7} \mathrm{We}_{\mathrm{S}}^{-\frac{3}{5}}\left[1+C_{8} \mathrm{Vi}_{\mathrm{C}}\left(\frac{\bar{d}_{32}}{D}\right)^{\frac{1}{3}}\right]^{\frac{3}{5}}
$$

Where their dimensionless viscosity group $\mathrm{Vi}_{\mathrm{C}}$ is the ratio of the viscous energy of the dispersed phase to the surface energy $\left(\mathrm{Vi}_{\mathrm{C}}=\mu_{d} N D\left(\rho_{c} / \rho_{d}\right)^{1 / 2} \sigma^{-1}\right)$. If $\mathrm{Vi}_{\mathrm{C}} \rightarrow 0$ Equation 10 reduces to Equation 7; on the other hand if $\mathrm{Vi}_{\mathrm{C}}$ is very large, the interfacial forces become negligible and Equation 10 reduces to

$$
\frac{\bar{d}_{32}}{D}=C_{9}\left(\frac{\rho_{c}}{\rho_{d}}\right)^{\frac{3}{8}}\left(\frac{\mu_{d}}{\mu_{c}}\right)^{\frac{3}{4}} \operatorname{Re}^{-\frac{3}{4}}
$$

Where $\operatorname{Re}$ is the Reynolds number $\operatorname{Re}=\rho_{c} N D^{2} \mu_{c}^{-1}$. As noted by the authors as $\mu_{c}$ is contained within Re thus Equation 11 has no dependency on $\mu_{c}$. Calabrese et al. ${ }^{10}$ performed a long series of experiments using five silicon oils (SiOils) as dispersed phase within the $9.60 \times 10^{-2} \mathrm{Pas}$ to $1.05 \times 10^{1} \mathrm{Pas}$ viscosity range in distilled water in the absence of surfactant; $\sigma$ was constant for all the SiOils and water $\sigma=3.78 \times 10^{-2} \mathrm{Nm}^{-1}$. Equation 10 was able 
to describe the results obtained by Arai et al. ${ }^{16}$ and most of their own results, except the ones obtained with two most viscous SiOils (4.43 Pas and 10.5 Pas). For these two silicon oils SiOils, their results were well-correlated by ${ }^{10}$

$$
\frac{\bar{d}_{32}}{D}=2.1\left(\frac{\mu_{d}}{\mu_{c}}\right)^{\frac{3}{8}} \operatorname{Re}^{-\frac{3}{4}}
$$

The droplet size dependency on $\mu_{d}$ for these SiOils was approximately half of the one in Equation 11 despite the large $\mathrm{Vi}_{\mathrm{C}}$. This equation suggests that there is a $\mu_{c}$ dependency, but the authors did not perform any experiments to prove such dependency.

In the second part of these studies, Wang and Calabrese ${ }^{14}$ changed $\sigma$ systematically by using different methanol in water solutions for SiOils in the $1.0 \times 10^{-3} \mathrm{~Pa}$ s to $1.0 \mathrm{Pas} \mu_{d}$ range and $1.0 \times 10^{-3} \mathrm{~N} \mathrm{~m}^{-1}$ to $4.5 \times 10^{-2} \mathrm{~N} \mathrm{~m}^{-1}$ for the $\sigma$ range. They found that as $\mu_{d}$ increases the influence of $\sigma$ decreases.

The DSD may be represented by frequency or density distribution curves $f\left(d_{i}\right)$ or by their cumulative curves $F\left(d_{i}\right)$. For emulsions these are commonly by number $\left(f_{n}\left(d_{i}\right)\right.$ and $\left.F_{n}\left(d_{i}\right)\right)$ or by volume $\left(f_{v}\left(d_{i}\right)\right.$ and $\left.F_{v}\left(d_{i}\right)\right)$. Two emulsions may have different DSDs despite having the same mean droplet size. There have been numerous attempts to describe the droplet size distributions obtained in stirred vessels and in rotor-stators; some of the distribution functions used are summarized in Table 1.

Multimodality has been explicitly mentioned by several of authors listed in Table $1^{9,23,25,26,28,29}$ while others ${ }^{10,14}$ found that the DSD broadens as $\mu_{d}$ increases. The broadening has been attributed to a change in the droplet breakup mechanism from bursting towards stretching by several of the aforementioned authors. 
Table 1: Types of Distributions used by Several Authors to fit the DSD.

\begin{tabular}{|c|c|}
\hline & Function(s) \\
\hline \multirow[b]{2}{*}{$F_{n}\left(d_{i}\right)$} & Normal $^{9,10,17}$ \\
\hline & Log-normal $^{10,18,19}$ \\
\hline \multirow{2}{*}{$f_{n}\left(d_{i}\right)$} & Log-normal $^{13,20}$ \\
\hline & Fréchet $^{11,21}$ \\
\hline \multirow{4}{*}{$F_{v}\left(d_{i}\right)$} & Schwarz and Bezemer ${ }^{8}$ \\
\hline & Normal $^{10,14,18,22}$ \\
\hline & Multiple Normal $^{9}$ \\
\hline & Log-normal ${ }^{10,23}$ \\
\hline \multirow{3}{*}{$f_{v}\left(d_{i}\right)$} & Normal $^{24,25}$ \\
\hline & Log-normal $^{26}$ \\
\hline & Generalized Gamma $^{27}$ \\
\hline
\end{tabular}

Figure 1 shows the viscosity ratio of the dispersed and continuous phase used in some of the most relevant studies in the field in chronological order. Despite the numerous studies on emulsification using stirred vessels and rotor-stators, it becomes evident that the effect of viscosity on polydispersity has not been addressed.

When bimodality is present, regularly one or several of the four approaches listed below is used

- Fit to the cumulative distribution. As noted by Pacek et al. ${ }^{23}$, cumulative distributions tend to smooth out detailed variations.

- Truncate the distribution that does not follow the trend ${ }^{25,30}$

- Nishikawa et al. ${ }^{9}$ used two normal density functions to fit the distribution by number and three to describe the one by volume.

- Convert the distribution by volume to a distribution by number ${ }^{10,11,21}$ which diminishes the contribution of the large drops. 


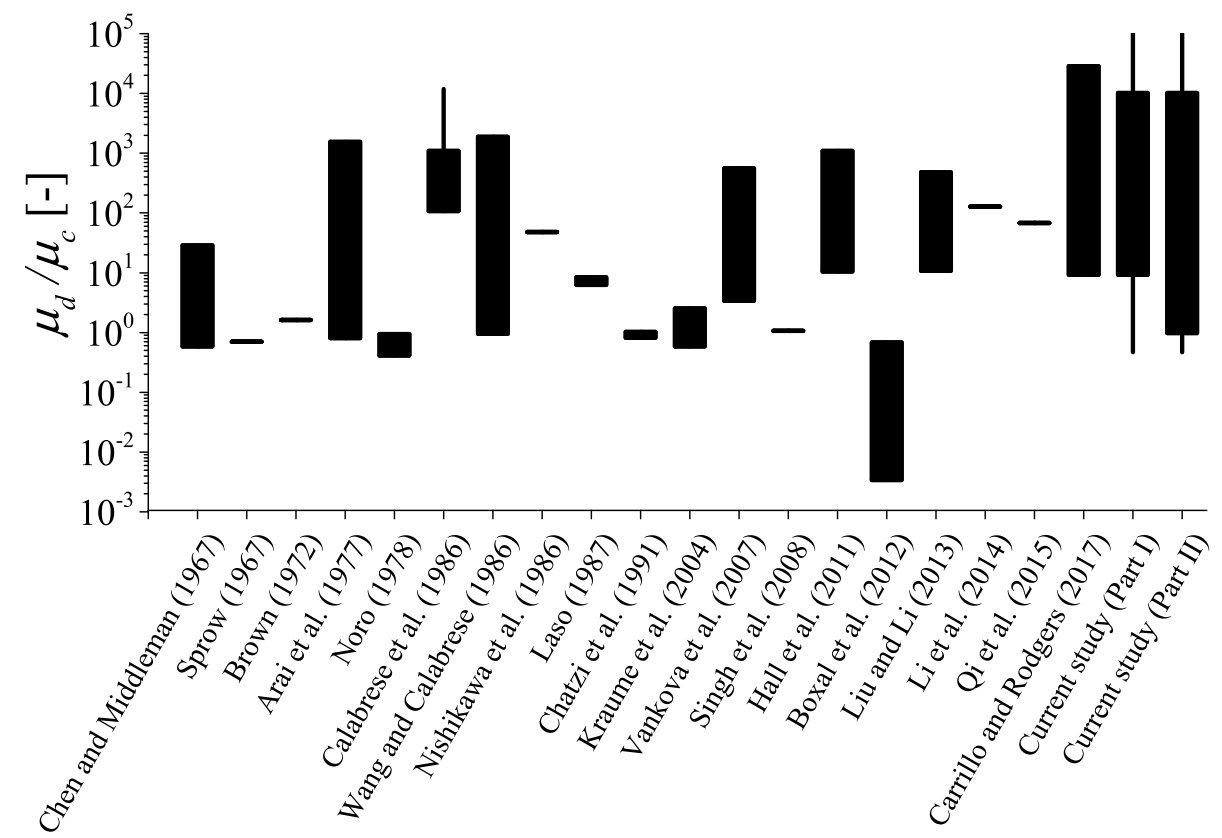

Figure 1: Viscosity ratio $\mu_{d} / \mu_{c}$ in relevant experimental studies on emulsification ${ }^{1,8-11,13,14,16-22,24-29}$. The extended line for the study of Calabrese et al. ${ }^{10}$ implies that different equations were used to fit each viscosity ratio range (see Eqs. 11 and 12).

Calabrese et al. ${ }^{10}$ found that a linear-normal distribution by number or volume could describe their DSD for low to moderate $\left(1.0 \times 10^{-3} \mathrm{Pas}\right.$ to $5.0 \times 10^{-1} \mathrm{Pas}$ ) dispersed phases. But for their high-viscosity oils (5.0 Pa s to $10 \mathrm{~Pa}$ s) the largest $1 \%$ of the drops contained $70 \%$ of the emulsions volume, therefore their data could only be represented using a log-normal distribution by number.

Zhou and Kresta ${ }^{31}$ used four different types of impeller at different impeller speeds and off-bottom clearances and measured to study the DSD of very dilute emulsions. They classified their DSD into four categories and suggested different distribution functions for each case: (1) Long tail distribution represented by a normal distribution; (2) double peak distribution by 
superimposing two normal distributions; (3) skew distribution which could be represented by a Poisson distribution, an exponential distribution, a Gamma distribution or two superimposed normal distributions; and (4) skew-normal distribution which can be approximated by a normal distribution.

Chatzi et al. ${ }^{29}$ attributed the scarce amount of literature reporting bimodality on the inaccuracy of the photographic methods while Laso et al. ${ }^{28}$ noted that in photographic methods the observers tend to neglect small droplets and focus on the larger ones. The DSD analysis before 1990 included

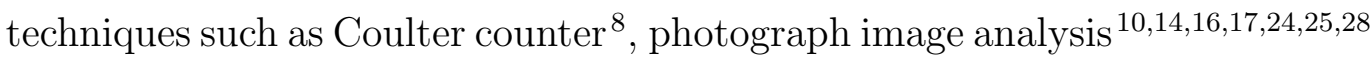
and microscopy ${ }^{9}$.

In our previous study ${ }^{27}$ we studied the effect of $\mu_{d}$ on the $f_{v}\left(d_{i}\right)$ for rotorstator mixers using a multiple fit Generalized Gamma function. The DSD obtained in the aforementioned study showed two distinctive peaks which could be fit as the mode of the daughter drops $M o_{d}$ and the mode of the satellite drops $\mathrm{Mo}_{s}$ of each distribution was easily obtainable. The present study resulted more challenging as the $f_{v}\left(d_{i}\right)$ of the two types of daughter droplets were merged together in most of the DSD and the trends are more difficult to quantify.

In Part I of this study, the combined effects of $\mu_{d}$ and $N$ of dilute emulsions (1 v.\%) with an excess of surfactant-to hinder cohesive interfacial forces- on the droplets size and DSD are studied. Throughout this investigation we intend to broaden the understanding of the droplet breakup process by providing a characterization of the $f_{v}\left(d_{i}\right)$ as bimodality arises for viscid dispersed phases.

In Part $\mathrm{II}^{1}$, we investigated the effect of $\mu_{c}$ on the DSD for experiments 
at constant Po; according to the theory reviewed in this section, the drop size and DSD should be independent of $\mu_{c}$ if Po is constant, and if emulsification occurs in the turbulent inertia regime; however this is was not the case. Part II ${ }^{1}$ offers an explanation by discussing the limitations of the Kolmogorov $-5 / 3$ energy spectrum.

The narrow bars in Figure 1 (for the current studies: Parts I and $\mathrm{II}^{1}$ ) represent the experimental range while the thick bars represent the range on which modelling was undertaken.

\section{Materials and equipment and methods}

\subsection{Materials}

Nine 200 Fluid XX Silicone Oil (dimethyl siloxane, Dow Corning, Michigan, U.S.A.) where "XX" stands for their nominal dynamic viscosity in centistokes [cSt], which will be used to facilitate discussion. Silicon Oils (SiOil) SiOils are available over a wide range of viscosity, their shear viscosity is independent of shear rate and their densities and interfacial tensions are similar for most of them. Four additional SiOils with intermediate viscosities labelled as $2800 \mathrm{cSt}, 4500 \mathrm{cSt}, 7600 \mathrm{cSt}$ and $50000 \mathrm{cSt}$ were obtained by mixing. The list of the SiOils and relevant properties are listed in Table 2.

The densities $\rho_{d}$ were taken as given by the provider. The viscosities $\mu_{d}$ were measured using a DV2T Viscometer (Brookfield Vicometers, Essex, UK). The refractive index $n_{r i}$ of SiOils were determined using a RFM390 Refractometer (Belling-ham and Stanley Ltd, Kent, UK).

Calabrese et al. ${ }^{10}$ raised some concerns about some high viscosity SiOils behaving as Boger fluids: shear viscosity independent of shear rate but with 
Table 2: Density $\rho_{d}$, viscosity $\mu_{d}$ and refractive index $n_{r i}$ for the SiOils used at $25^{\circ} \mathrm{C}$.

\begin{tabular}{rccc}
\hline $\begin{array}{r}\text { SiOil } \\
{[\mathrm{cSt}]}\end{array}$ & $\begin{array}{c}\rho_{d} \\
{\left[\mathrm{~kg} \mathrm{~m}^{-3}\right]}\end{array}$ & $\begin{array}{c}\mu_{d} \\
{[\mathrm{~Pa} \mathrm{~s}]}\end{array}$ & $\begin{array}{c}n_{r i} \\
{[-]}\end{array}$ \\
\hline 0.65 & 750 & $4.88 \times 10^{-4}$ & 1.375 \\
10 & 934 & $9.58 \times 10^{-3}$ & 1.399 \\
50 & 960 & $4.91 \times 10^{-2}$ & 1.402 \\
350 & 970 & $3.28 \times 10^{-1}$ & 1.403 \\
1000 & 970 & $9.47 \times 10^{-1}$ & 1.404 \\
$* 2800$ & 970 & $2.75 \times 10^{0}$ & 1.404 \\
$* 4500$ & 970 & $4.34 \times 10^{0}$ & 1.404 \\
$* 7600$ & 970 & $7.36 \times 10^{0}$ & 1.404 \\
10000 & 970 & $1.05 \times 10^{1}$ & 1.404 \\
12500 & 970 & $1.33 \times 10^{1}$ & 1.404 \\
30000 & 970 & $2.93 \times 10^{1}$ & 1.404 \\
${ }^{\top} 50000$ & 970 & $4.88 \times 10^{1}$ & 1.404 \\
100000 & 970 & $1.06 \times 10^{2}$ & 1.404 \\
\hline *Obtained by mixing the 1000 and $10000 \mathrm{cSt}$ SiOils. \\
${ }^{\top}$ Obtained by mixing the 30000 and $100000 \mathrm{cSt}$ SiOils.
\end{tabular}

a an extensional viscosity dependent on extensional strain rate. The extensional properties of the 1000, 10 000, 30000 and 100000 cSt SiOils were investigated using a HAAKE CaBer (Thermo Fischer Scientific, Massachusetts, USA). All the SiOils behaved as Newtonian fluids under the experimental strain rates. This study can be consulted in the Supplementary material attached to this paper.

As continuous phase we used a 1.0 wt.\% sodium laureth sulfate (SLES) aqueous solution. The surfactant used was Texapon N701 (Cognis, Hertfordshire, UK) which contains approximately $70 \%$ concentration by weight of SLES and approximately 30\% water and impurities. SLES is an anionic surfactant with molar mass and density equal to $420 \mathrm{~g} \mathrm{~mol}^{-1}$ and $1030 \mathrm{~kg} \mathrm{~m}^{-3}$ respectively. El-Hamouz ${ }^{32}$ determined that its critical micelle concentration 
is $8.4 \times 10^{-2} \mathrm{~g} \mathrm{~L}^{-1}$, the concentration used in this investigation is approximately 120 times higher.

The interfacial tension were measured using a K11 Mk4 Tensiometer (KRUSS, Hamburg, Germany) with a $9.545 \mathrm{~mm}$ platinum-iridium ring. Measuring the interfacial tension for SiOils above a $1000 \mathrm{cSt}$ was not possible with this method because the tensiometer overestimates the maximum lamella height and breaks it. The $\sigma$ between the $0.65 \mathrm{cSt}, 10 \mathrm{cSt}$ and $350 \mathrm{cSt}$ SiOils and the continuous phases are shown in Table 3. The interfacial tension increases for the two most viscous SiOils is very similar, therefore the interfacial tension for the SiOils with viscosities greater than $350 \mathrm{cSt}$ was assumed constant, as done by Calabrese et al. ${ }^{10}$ and Hall et al. ${ }^{26}$.

Table 3: Interfacial tensions of the SiOils and the continuous phases. The percentages represent one standard deviation.

\begin{tabular}{cc}
\hline SiOil $[\mathrm{cSt}]$ & $\sigma\left[\mathrm{mN} \mathrm{m}^{-1}\right]$ \\
\hline 0.65 & $6.08 \pm 1.2 \%$ \\
10 & $9.25 \pm 3.0 \%$ \\
350 & $9.43 \pm 3.9 \%$ \\
\hline
\end{tabular}

\subsection{Equipment}

A 6-bladed pitched turbine inclined $45^{\circ}$ with $D=4.83 \times 10^{-2} \mathrm{~m}$ was used as impeller. The turbine was coupled with a RW20 (IKA-WERKE, Staufen, Germany). The tank had a diameter $T$ of $1.37 \times 10^{-1} \mathrm{~m}(D / T \approx 0.35)$ and four baffles. The size of the baffles, clearance and the height of the liquid were $T / 10, T / 3$ and $T$ respectively. The volume of the vessel $V$ was $1.97 \mathrm{~L}$.

The DSD was obtained using an off-line laser diffraction particle size analyser, the Mastersizer 3000 (Malvern Instruments, Malvern, UK), which allows to measure drops in the $10^{-3} \mu \mathrm{m}$ to $3 \times 10^{3} \mu \mathrm{m}$ range. 


\subsection{Method}

\subsubsection{Emulsification}

Once the continuous phase was poured into the vessel, the desired rotational speed of the impeller was fixed using a CT6 Hand-Held Tachometer (Compact Instruments, Lancashire, UK) and $20 \mathrm{~mL}$ of SiOil were injected in the impeller vicinity using a syringe. The concentration of the SiOil was $1.0 \%$ by volume.

The emulsification time for all experiments was $24 \mathrm{~h}$ and steady-state was verified by comparing the DSDs obtained after $24 \mathrm{~h}$ and $72 \mathrm{~h}$ for the 10 and 10000 cSt SiOils for $N=8.33 \mathrm{~s}^{-1}$.

As seen in Table $2, \mu_{d}$ was varied across several orders of magnitude. The effect of $\mu_{d}$ and $N$ was assessed by emulsifying the SiOils listed in Table 2 in the Water/SLES solution at five different $N: 8.33 \mathrm{~s}^{-1}, 10.0 \mathrm{~s}^{-1}, 11.7 \mathrm{~s}^{-1}$, $13.3 \mathrm{~s}^{-1}$ and $15 \mathrm{~s}^{-1}$.

The total number of emulsions prepared was 65, nevertheless the emulsions prepared with $7600 \mathrm{cSt}$ and $10000 \mathrm{cSt}$ SiOil for the lowest stirring speeds $\left(8.33 \mathrm{~s}^{-1}\right.$ and $\left.10.0 \mathrm{~s}^{-1}\right)$ could not be analysed because the largest droplets were beyond the measuring limit of the instrument and due to the large diameter span of the DSD spreading across three orders of magnitude.

\subsubsection{Droplet Size Analysis}

Samples were taken at the impeller vicinity using a syringe with a modified larger hub not to cause further droplet break up. Samples were analysed right after sampling to ensure that no changes in the DSD would occur, despite that emulsion stability was verified for a period of $72 \mathrm{~h}$ after emulsification. At least three samples were analysed for each emulsion. Drops of 
the sample were added to the Hydro EV dispersion units until reaching an obscuration rate of about $5-11 \%$.

The analysis model chosen in the instrument's software was "General purpose" to ensure that bimodal effects were not suppressed. Three measurement cycles of $30 \mathrm{~s}$ were performed for the emulsions containing the 0.65 cSt -2760 cSt SiOils whereas measurement cycles of $300 \mathrm{~s}$ were needed for the most viscous SiOil. This was necessary due to the polydispersity of the droplets, increasing the analysis time allowed consistency in the measurements for the same sample. The $n_{r i}$ for the dispersed phases are the ones listed in Table 2 and the absorption index used was $1 \times 10^{-3}$ as recommended by Malvern for transparent droplets under the microscope.

\section{Results and discussion}

\subsection{Phenomenology}

In this section some of the results will be presented to show the effect of $\mu_{d}$ and $N$ on the shape of the DSD. Two different behaviours were found for the 0.65 -10000 cSt SiOils and the 12 500-100000 cSt SiOils. In the former $\mu_{d}$ range, droplet size increased with $\mu_{d}$ and decreased with $N$; for the latter viscosity range, the maximum droplet size was independent of $\mu_{d}$ and $N$.

The effect of $\mu_{d}$ for the SiOils in the $0.65 \mathrm{cSt}-10000 \mathrm{cSt}$ viscosity range for $N=11.7 \mathrm{~s}^{-1}$ is shown in Figure $2 \mathrm{a}$ in a semi-log plot. As expected, the droplet size increases with $\mu_{d}$ and the DSD broadens. The 0.65 cSt, 10 cSt and 50 cSt SiOils yielded monomodal distributions while the rest were bimodal, presumably due to a change in the drop breakup mechanism that produces satellite droplets. 
High speed image processing of drop breakup events have shown that drop breakup is seldom a binary process ${ }^{33-36}$. Andersson and Andersson ${ }^{34}$ observed that prior to breakup, droplets stretch and acquire a dumbbell shape with two spherical ends connected by a cylinder and that the liquid threats could be even longer than 20 times their original diameter. Eastwood et al. ${ }^{33}$ and Nachtigall et al. ${ }^{35}$ found that the drops stretch several times their original diameter and that this stretching increases with the viscosity of the dispersed phase. The appearance of a secondary type of drops was attributed to breakup of dumbbell-shaped drops: (1) large daughter drops correspond to the spherical ends of the dumbbell-shaped drops and (s) small daughter drops to the breakup of the cylinder in-between the ends.

Figure $2 \mathrm{~b}$ shows the effect of $N$ on the DSD for the $1000 \mathrm{cSt}$ SiOil. As expected the droplet size decreases with $N$. This is true for the daughter and satellite droplets.

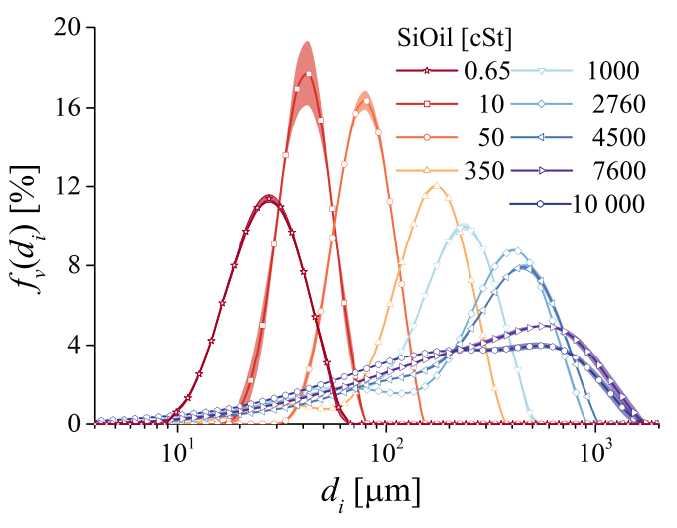

(a)

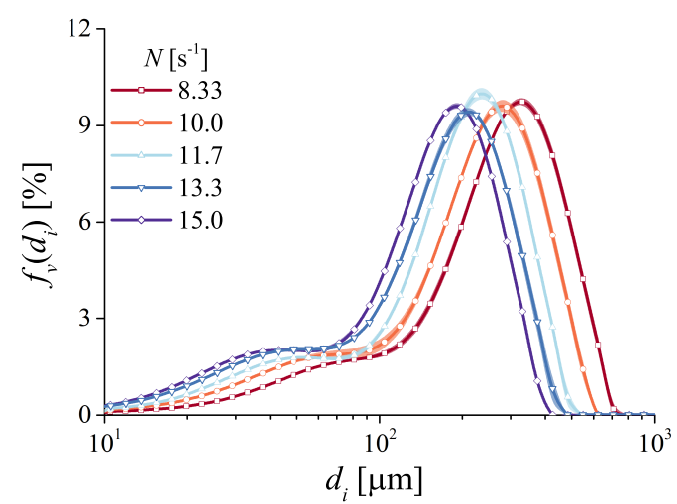

(b)

Figure 2: Examples of the resulting DSD of systems emulsified. (a) DSD for SiOils for in the $0.65 \mathrm{cSt}-10000 \mathrm{cSt}$ viscosity range for $N=11.7 \mathrm{~s}^{-1}$. (b) DSD for the $1000 \mathrm{cSt}$ SiOil for different $N$. The shadowed areas represent one standard deviation from the mean. 
Figure 3 shows the DSD for the second type of behaviour encountered where the maximum drop size is independent of $\mu_{d}$ (see Fig. 3a) and $N$ (see Fig. 3b).

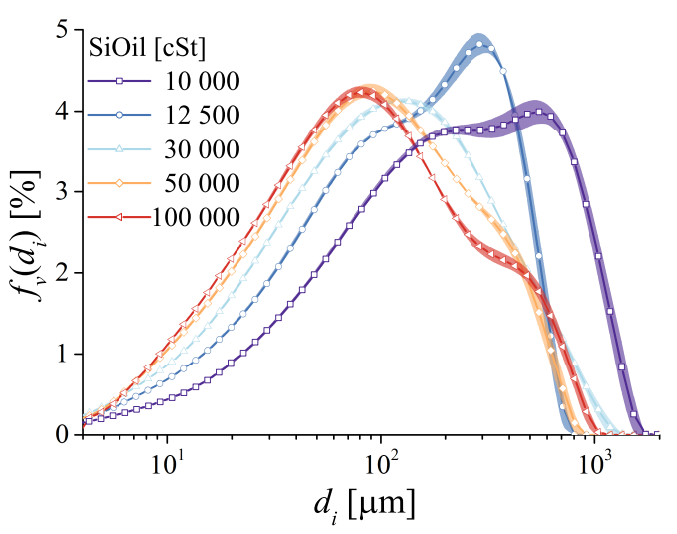

(a)

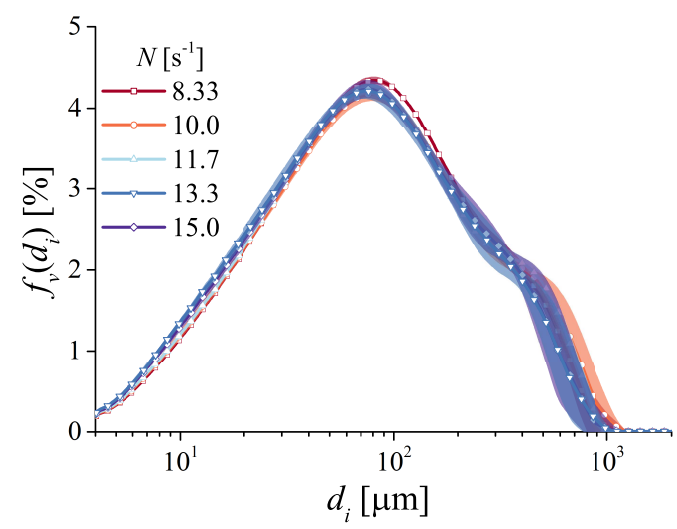

(b)

Figure 3: Examples of the resulting DSD of systems emulsified. (a) DSD for SiOils for in the $10000-100000 \mathrm{cSt}$ viscosity range for $N=11.7 \mathrm{~s}^{-1}$. (b) DSD for the $100000 \mathrm{cSt}$ SiOil for different $N$. The shadowed areas represent one standard deviation from the mean.

Figure 4 shows the $\bar{d}_{32}$ as a function of $\mu_{d}$ with $N$ as parameter. The vertical dashed delimits the two types of behaviours mentioned above. For the first type of behaviour (left of the dashed line), where $d_{\max }$ is $\mu_{d}$ and $N$ dependent, $\bar{d}_{32}$ increases with viscosity and levels off before decreasing sharply despite $d_{\max }$ increasing. This behaviour is due to the appearance of satellite drops, which amount increase with $\mu_{d}$ as was previously shown in Figure 2a. Furthermore the curves for different $N$ are parallel.

The $\bar{d}_{32}$ for the SiOils with viscosity equal and above $12500 \mathrm{cSt}$ were plotted at the right side of the dashed line in Figure 4; this zone is characterized by $d_{\text {max }}$ being independent of $\mu_{d}$ and by a decrease in $N$ dependency; all the curves seem to converge at the maximum $\mu_{d}$. 


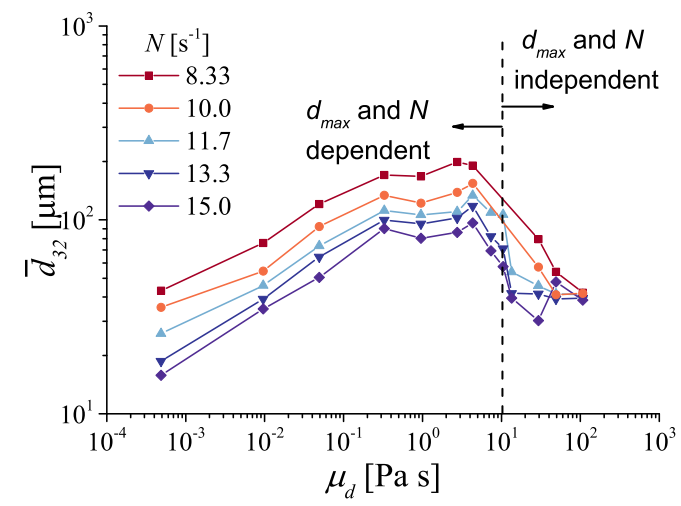

Figure 4: Effect of $\mu_{d}$ on the $\bar{d}_{32}$ with $N$ as parameters.

Equation 8 was tested for our emulsions using the 95th percentile as an approximation of $d_{\max }$. Figure 5 shows the evolution of the $\bar{d}_{32}$ to $d_{\max }$ ratio. It can be seen this ratio was constant for our monomodal emulsion while decreasing with $\mu_{d}$ for our bimodal distribution. No clear trend was found for the most viscous SiOils; as explained above, these had a different behaviour. However, this plot reveals that assuming a constant $\bar{d}_{32} / d_{\max }$ result in a tenfold-miscalculation in this region.

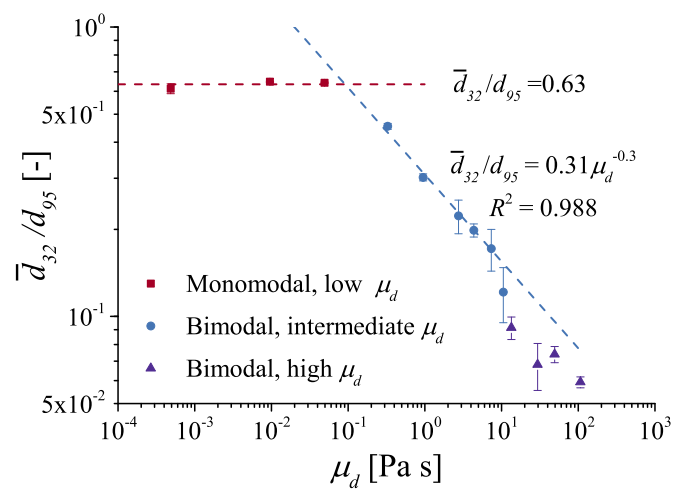

Figure 5: $\bar{d}_{32}$ to $d_{95}$ ratio as a function of $\mu_{d}$. The error bars represent one standard deviation from the mean.

294 Even though the experimental viscosity range used by Calabrese et al. ${ }^{10}$ 
is included in our study, we did not observe a low viscosity $d_{32}$-plateau for the viscosity range where, according to their mechanistic model, interfacial forces are the primarily force resisting drop breakup. As explained by Wang and Calabrese ${ }^{14}$, this is attributed to the lower interfacial tensions in our systems as the systems emulsified by Calabrese et al. ${ }^{10}$ were surfactant-free.

\subsection{Drop size}

The drop size analysis was performed using the mode of the daughter drops $M o_{d}$, alternatively $d_{\max }$ could be used; but we considerer the former statistically more significant and is consistent with our previous work ${ }^{27}$. In Section 3.3 the DSD will be standardized by $M o_{d}\left(f_{v}\left(d_{i} / M o_{d}\right)\right)$ and it will become evident that $M o_{d} \propto d_{\max }$ and why this was used. The analysis in this Section was only performed for the SiOils thinner than the $12500 \mathrm{cSt}$ SiOils.

Figure 6 shows the mode of the daughter droplets $M o_{d}$ as a function of $\mu_{d}$. This curve shows a steady increase of $M o_{d}$ with $\mu_{d}$ for each $N$ compared to the $\bar{d}_{32}$ shown previously where a plateau and decrease were observed. The comparison in-between Figures 4 and 6 show that $\bar{d}_{32}$ is not the best measure of central tendency to elucidate the drop break-up mechanism when the DSD are multimodal.

However, it can be noticed that the data obtained by the thinnest SiOil (0.65 cSt) does not follow the same trend as the thicker SiOils. This is attributed to its different properties (see Table 2) and $\sigma$ (see Table 3 ); furthermore Figure 2a shows that this oil produced a broader DSD than the other subsequent oils which also yielded monomodal distributions. Following Equation 7 , the a $M o_{d} D^{-1} \mathrm{We}_{\mathrm{S}}^{3 / 5}$ against $\mu_{d}$ should collapse the data- 


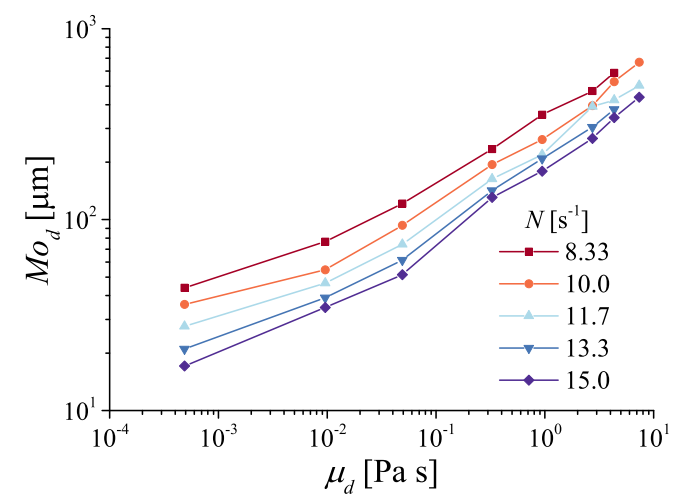

Figure 6: Effect of $\mu_{d}$ on the $M o_{d}$ with $N$ as parameters.

points creating a master-curve. As shown in Figure 7, this standardization successfully collapses the data points for different $N$, furthermore the curve resembles the ones presented by Calabrese et al. ${ }^{10}$ and Wang and Calabrese ${ }^{14}$ where a drop size-plateau (interfacial forces dominate) is followed by a drop size increase (as viscous forces become important). This Figure aids in delimiting the boundary of our study to the $10 \mathrm{cSt}$ - $10000 \mathrm{cSt}$ SiOils where viscous cohesive forces dominate.

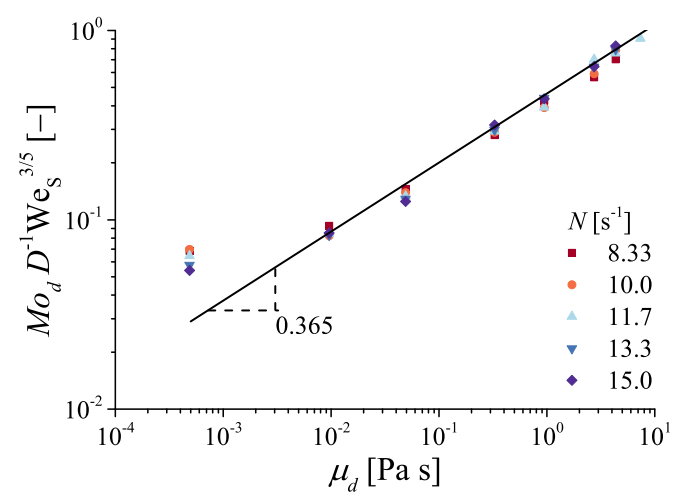

Figure 7: Dimensionless standardized $M o_{d}$ as a function of $\mu_{d}$.

27 A fit was performed for the emulsions with SiOils in the 10 cSt -10000 
cSt viscosity range with a fixed $M o_{d} \propto N^{-1.2}$ dependency.

$$
\frac{M o_{d}}{N^{-\frac{6}{5}}}=A_{1} \mu_{d}^{A_{2}}
$$

The values of the fitting constants, their $95 \%$ Confidence Interval and $p$-value are listed in Table 4.

Table 4: Fitting parameters for Equation 13.

\begin{tabular}{ccc}
\hline Parameter & Coefficient & $p$-value \\
\hline$A_{1}$ & $4.64 \times 10^{3} \pm 2.94 \%$ & $5.1 \times 10^{-59}$ \\
$A_{2}$ & $0.365 \pm 3.29 \%$ & $1.4 \times 10^{-31}$ \\
\hline
\end{tabular}

The coefficient of determination $R^{2}$ and the mean absolute error $M A E$ of the fit were 0.986 and $5.39 \%$ respectively. Our dependency on $\mu_{d}$ disagrees with most mechanistic models found in literature; the models proposed by Arai et al. ${ }^{16}$ and Calabrese et al. ${ }^{10}$ state that $A_{2}=0.75$ and the model proposed by Davies ${ }^{37}, A_{2}=0.6$. For their most viscous oils, Calabrese et al. ${ }^{10}$ could not fit their results using their mechanistic model and proposed an empirical correlation with $A_{2}=3 / 8$ (Eq. 12), which is very similar to the value found throughout our investigation. In our previous study on the effect of dispersed phase viscosity in rotor-stators ${ }^{27}$ we found $A_{2}=0.375$, suggesting that $A_{2}$ is independent of the mechanical stirred apparatus used.

\subsection{Droplet size distribution modelling}

The DSD were normalized by $M o_{d}$ to show the changes in the shape of the DSD. Figure $8 \mathrm{a}$ shows the effects of $\mu_{d}$ for constant $N$ and Figure $8 \mathrm{~b}$ shows the effect of $N$ on the DSD for the 1000 cSt Silicon Oil SiOil. The former Figure 8a shows that the DSDs become broader and that the amount 


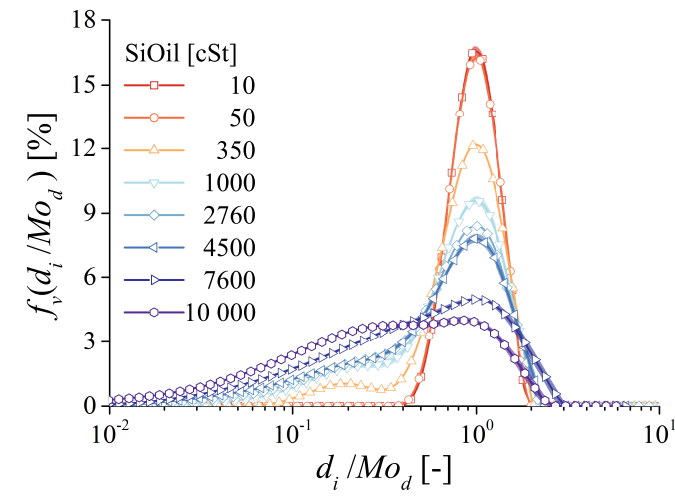

(a)

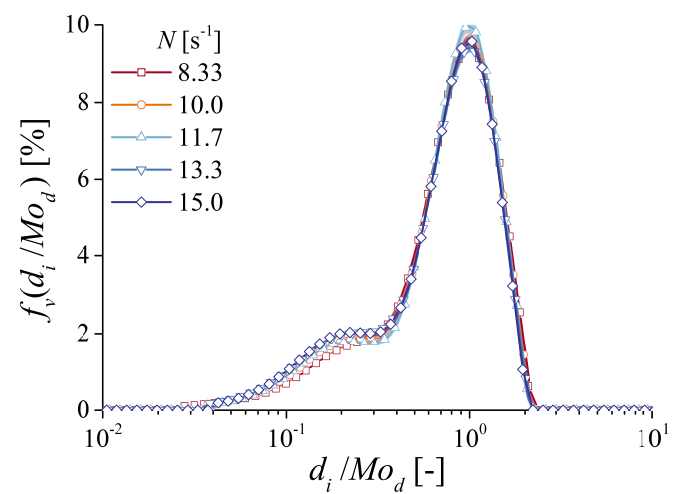

(b)

Figure 8: Normalized DSD $f_{v}\left(d_{i} / M o_{d}\right)$ (a) for different SiOils for $N=13.3 \mathrm{~s}^{-1}$ and (b) for the $1000 \mathrm{cSt}$ SiOil for different $N$.

The DSDs were modelled by fitting two log-normal distributions functions $\left(p\left(d_{i} / M o_{d}\right)\right)$ to the $M o_{d}$-standardized DSD by volume. The $p\left(d_{i} / M o_{d}\right)$ were normalized so that the sum of the frequencies equals $100 \%$. The equations of the log-normal distribution, its normalization and the mixing rule of the 
two distributions are given by

$$
\begin{aligned}
p\left(\frac{d_{i}}{M o_{d}}\right) & =\frac{1}{s_{z} \sqrt{2 \pi}\left(\frac{d_{i}}{M o_{d}}\right)} \exp \left\{-\frac{\left[\ln \left(\frac{d_{i}}{M o_{d}}\right)-\bar{z}\right]^{2}}{2 s_{z}^{2}}\right\} \\
f_{v}\left(\frac{d_{i}}{M o_{d}}\right) & =100 \times \frac{p\left(\frac{d_{i}}{M o_{d}}\right)}{\sum p\left(\frac{d_{i}}{M o_{d}}\right)} \\
f_{v, T}\left(\frac{d_{i}}{M o_{d}}\right) & =\left(1-\phi_{s}\right) f_{v, d}\left(\frac{d_{i}}{M o_{d}}\right)+\phi_{s} f_{v, s}\left(\frac{d_{i}}{M o_{d}}\right)
\end{aligned}
$$

Where $s_{z}$ is the standard deviation of $\log \left(d_{i} / M o_{d}\right), \bar{z}$ is the arithmetic mean of $\log \left(d_{i} / M o_{d}\right), \phi_{s}$ is the volume fraction of the satellite drops; and $f_{v, T}\left(d i / M o_{d}\right), f_{v, d}\left(d i / M o_{d}\right)$ and $f_{v, s}\left(d i / M o_{d}\right)$ are the standardized frequency distribution by volume for the whole DSD, the daughter drops and the satellite drops respectively.

The expression for the mode $M o$ of a log-normal distribution function is $M o=\exp \left(\bar{z}-s_{z}^{2} / 2\right)$, therefore in the case of the $M o_{d}$-standardized DSD we obtain $\bar{z}=s_{z}^{2} / 2$ reducing the number of fitting parameters for $f_{v, d}\left(d_{i} / M o_{d}\right)$.

To fit the $M o_{d}$-standardized DSDs the following assumptions were made:

- The standard deviation of the daughter droplets $s_{z, d}$ is independent of $\mu_{d}$ and $N$ as $M o_{d} / d_{\max }$ is constant (see Fig. 8).

- The modes of both types of droplets are equidistant

$$
\begin{aligned}
\bar{z}_{s} & =\ln M o_{s}+\frac{s_{z, s}^{2}}{2} \\
& =A_{4}+\frac{s_{z, s}^{2}}{2}
\end{aligned}
$$


- The standard deviation of the satellite droplets is $N$-independent (see Fig. 8b), but has a power-law dependency on $\mu_{d}$ :

$$
s_{z, s}=A_{5} \mu_{d}^{A_{6}}
$$

- As $\phi_{s}$ for the monomodal distributions is zero, increases with $\mu_{d}$, the daughter droplets disappeared in short $\mu_{d}$-interval and is $N$-independent; we used a cumulative Weibull distribution to describe the effect of $\mu_{d}$ on $\phi_{s}$

$$
\phi_{s}=1-\exp \left[-\left(\frac{\mu_{d}}{\beta}\right)^{\alpha}\right]
$$

Where $\alpha$ and $\beta$ are fitting parameters.

Under these considerations listed above, the DSD were fitted for $s_{z, d}, A_{4}, A_{5}$, $A_{6}, \alpha$ and $\beta$ using the least absolute error in-between the experimental and modelled DSDs. The values obtained for the fit are shown in Table 5. Some examples of the fits are shown in Figure 9.

Table 5: DSD fit parameters.

\begin{tabular}{cc}
\hline Parameter & Coefficient \\
\hline$s_{z, d}$ & 0.40 \\
$A_{4}$ & -0.87 \\
$A_{5}$ & 0.80 \\
$A_{6}$ & 0.15 \\
$\alpha$ & 1.4 \\
$\beta$ & 2.0 \\
\hline
\end{tabular}

73 The value we obtained for $s_{z, d}$ is considerably larger than the ones of Chen and Middleman ${ }^{24}$ and Wang and Calabrese ${ }^{14}$ who reported values of 0.23 and 0.24 respectively. 


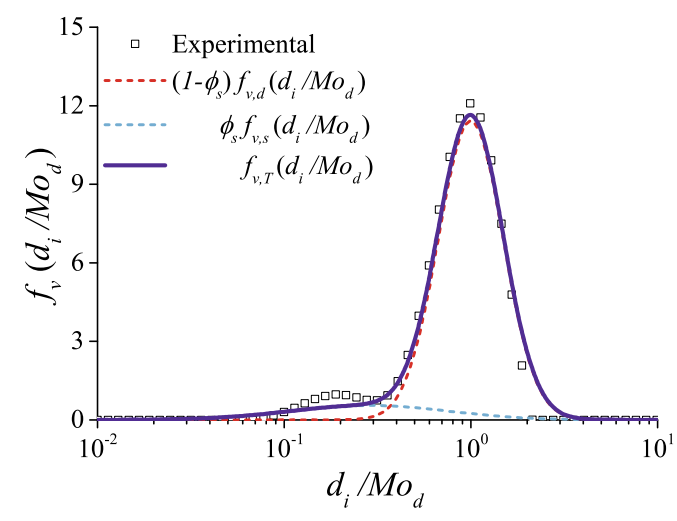

(a)

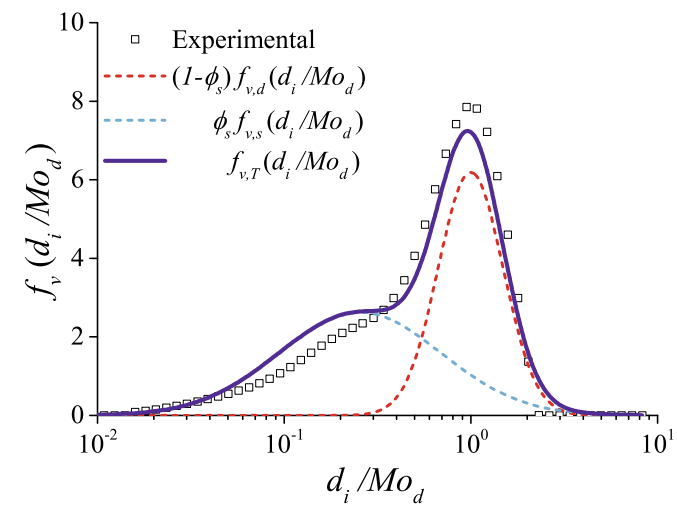

(c)

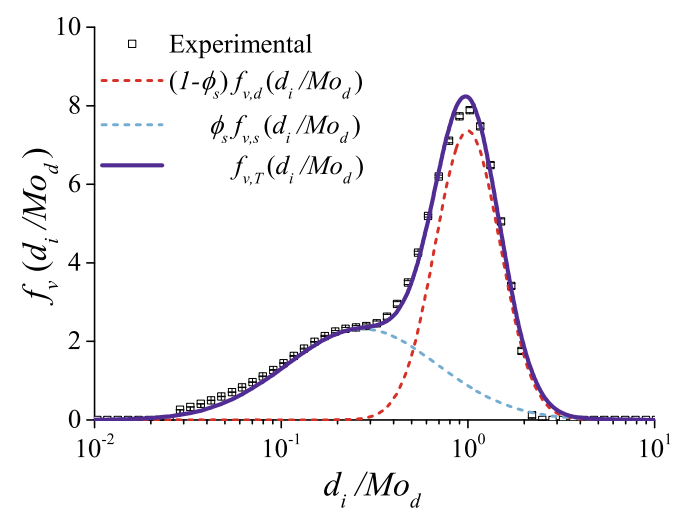

(b)

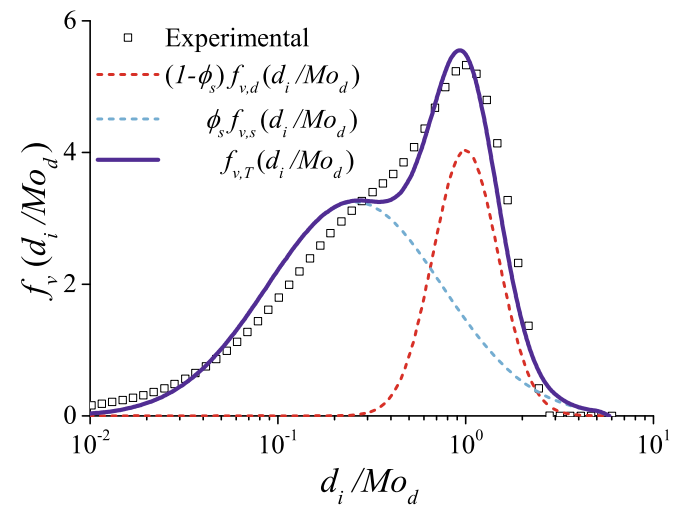

(d)

Figure 9: Random fitting examples to $M o_{d}$-standardized DSD: (a) $350 \mathrm{cSt}$ SiOil and $N=8.33 \mathrm{~s}^{-1}$; (b) $2760 \mathrm{cSt}$ SiOil and $N=11.7 \mathrm{~s}^{-1}$; (c) $5370 \mathrm{cSt}$ SiOil and $N=10.0 \mathrm{~s}^{-1}$ and; (d) $10000 \mathrm{cSt}$ SiOil and $N=13.3 \mathrm{~s}^{-1}$.

Figure 10 shows the values of $\phi_{s}$ if it is allowed to fit "freely", while the line represents Equation 19 with its corresponding fit parameters found in Table 5. This Figure shows that a cumulative Weibull distribution is adequate for describing the $\phi_{s}$ dependency on $\mu_{d}$. Furthermore, it depicts why Equation 13 was not applicable for the thickest SiOils: the trend-line suggests that $\phi_{d} \approx 0$ for $\mu_{d}>30 \mathrm{Pas}$.

It is interesting noticing that the two DSD are equidistant, in our previous 


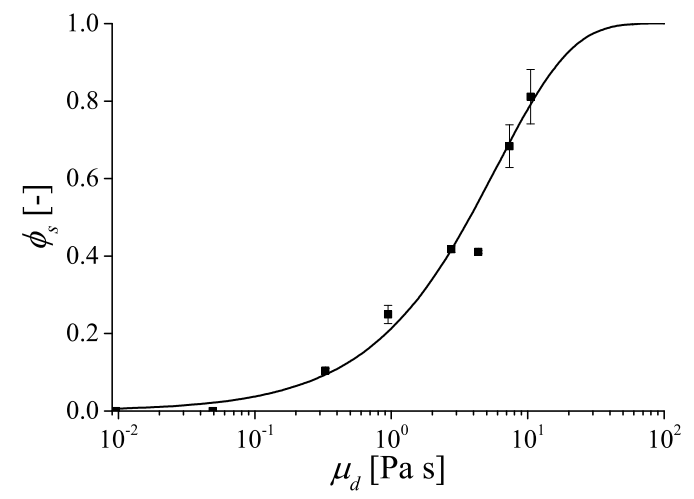

Figure 10: Volume fraction of satellite drops $\phi_{s}$ as a function of dispersed phase viscosity $\mu_{d}$ using water/SLES as continuous phase for five different stirring speeds.

study on the effect of viscosity in rotor-stators ${ }^{27}$ we found the same $M o_{d}$ dependency on $\mu_{d}$, but we found that the small droplets decreased with $\mu_{d}$ which was not the case for stirred vessels. The reason, a priori, is unknown.

The goodness of the fit can be assessed by comparing the $\bar{d}_{32}$ obtained with the fit with the experimental one. In the first subfigure a $N$-standardized $\bar{d}_{32}$ as a function of $\mu_{d}$ is shown; provided that Equation 8 is applicable for different $N$ and that $d_{\max } \propto N^{-6 / 5}$. It can be observed that our fit follows the trend of the experimental data. The second Figure uses direct comparison. The $R^{2}$ and $M A E$ are 0.82 and $12.2 \%$ respectively.

\section{Conclusions}

A wide number of SiOils with $\mu_{d}$ ranging across 6-orders of magnitude were emulsified to study the changes in the steady-state drop break-up mechanism. Three different regimes were observed, namely (1) the one where interfacial forces dominate and which has been described by Hinze ${ }^{2}$, Chen and Middleman ${ }^{24}$, Calabrese et al. ${ }^{10}$ and Calabrese et al. ${ }^{15}$ and many others. 


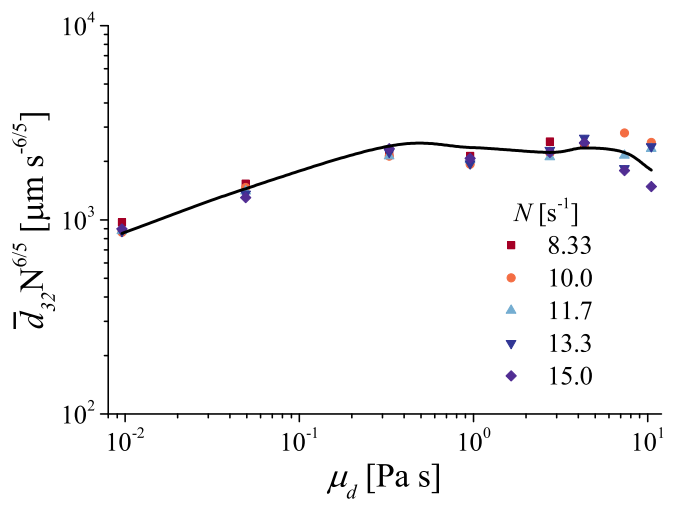

(a)

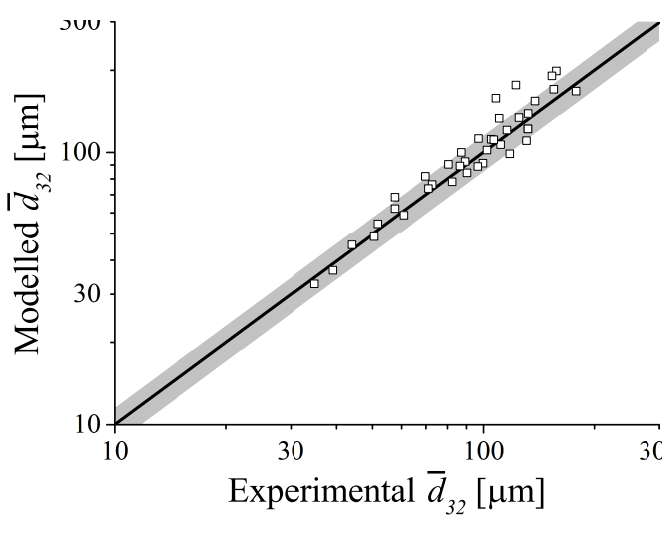

(b)

Figure 11: Goodness of the fit to the DSDs. (a) shows the $N$-standardized experimental and modelled $\bar{d}_{32}$ and (b) the goodness of the predicted $\bar{d}_{32}$.

(2) The regime where the drops' viscous resistance dominates which has been mainly described by Davies ${ }^{37}$, Calabrese et al. ${ }^{10}$ and Wang and Calabrese ${ }^{14}$. In this regime bimodal drop size distributions were observed for the SiOils in the 50-350 cSt range. Bimodality was also observed in the same $\mu_{d}$ range in our study on the effect of viscosity in rotor-stators ${ }^{27}$. (3) For very high $\mu_{d}$ we observed that the maximum drop sizes decrease and become independent of $N$; furthermore the steady-state $\bar{d}_{32}$ of these emulsion were smaller than the ones obtained for the $10 \mathrm{cSt}$ SiOils.

To describe the effect of $\mu_{d}$ on the drop sizes we used the $M o_{d}$, which was shown to be a better parameter than $\bar{d}_{32}$ while being proportional to $d_{\max }$ for all the experimental $\mu_{d}$ and $N$. The drop size correlated well with $\mu_{d}^{-0.365}$, which is in agreement with our previous work ${ }^{27}$, while being in disagreement with the work of Davies ${ }^{37}$, Calabrese et al. ${ }^{10}$,Wang and Calabrese ${ }^{14}$ and Vankova et al. ${ }^{18}$; the first three of these studies were done in the absence of surfactant, while the latter was performed did use surfactants. The sutler 
dependency of the DSD on $\mu_{d}$ could not been explained by any mechanistic model.

Finally a methodology to fit the bimodal DSD by volume using two lognormal distributions was proposed. The fit proposed could predict the $\bar{d}_{32}$ reasonably-well.

\section{Funding}

The authors would like to express their gratitude to the Mexican National Council for Science and Technology (CONACYT) for supporting this project as part of the first authors PhD studies through the CONACYT-The University of Manchester fellowship program.

\section{Acknowledgements}

We would like to express our gratitude to the Complex Formulations Department at Fresenius Kabi Deutschland GmbH and specially to Dr. Mihaela Turcanu for running the extensional rheometry tests, and for her help during the data analysis of the rheological data.

The authors would also like to thank the workshop staff of The University of Manchesters School of Chemical Engineering and Analytical Science for their help with the modifications and maintenance of the equipment.

\section{Bibliography}

1. Carrillo De Hert, S., Rodgers, T.L.. On the steady-state drop size distribution in stirred vessels. part ii: effect of continuous phase viscosity; 1993. Second part of this paper. 


\begin{tabular}{|c|c|c|c|}
\hline \multicolumn{4}{|c|}{ Nomenclature } \\
\hline \multicolumn{2}{|c|}{ Latin symbols } & $\alpha$ & parameter in the Weibull function [-] \\
\hline $\bar{d}_{32}$ & Sauter mean diameter $[\mu \mathrm{m}]$ & $\beta$ & parameter in the Weibull function [-] \\
\hline $\bar{d}_{p q}$ & generalized mean drop size $[\mu \mathrm{m}]$ & $\epsilon$ & energy dissipation rate per unit mass \\
\hline $\bar{z}_{d}$ & arithmetic mean of $\log \left(d_{i} / M o_{d}\right)$ of the & & {$\left[\mathrm{J} \mathrm{kg}^{-1} \mathrm{~s}^{-1}\right]$} \\
\hline \multirow{3}{*}{$\bar{z}_{s}$} & daughter drops $[-]$ & $\epsilon_{\max }$ & maximum energy dissipation rate per \\
\hline & arithmetic mean of $\log \left(d_{i} / M o_{d}\right)$ of the & & unit mass $\left[\mathrm{J} \mathrm{kg}^{-1} \mathrm{~s}^{-1}\right]$ \\
\hline & satellite drops [-] & $\eta$ & Kolmogorov length scale $[\mathrm{m}]$ \\
\hline $\begin{array}{l}A_{i}, C_{i} \\
a_{v}\end{array}$ & $\begin{array}{l}i \text { th constants }[-] \\
\text { interfacial area }\left[\mathrm{m}^{2}\right]\end{array}$ & $\mu_{c}$ & $\begin{array}{l}\text { dynamic viscosity of the continuous } \\
\text { phase }[\mathrm{Pas}]\end{array}$ \\
\hline & glucose concentration $\left[\mathrm{mol} \mathrm{L}^{-1}\right]$ & $\mu_{d}$ & dynamic viscosity of the dispersed phase \\
\hline & diameter of the stirrer $[\mathrm{m}]$ & & {$[\mathrm{Pas}]$} \\
\hline \multirow{6}{*}{$\begin{array}{l}d_{i} \\
d_{95} \\
d_{\text {max }} \\
F_{n} \\
f_{n} \\
F_{v} \\
f_{v} \\
f_{v, d}\end{array}$} & $\begin{array}{l}\text { diameter of the drop class } i[\mu \mathrm{m}] \\
\text { 95th percentile }[\mu \mathrm{m}]\end{array}$ & $\bar{\epsilon}$ & $\begin{array}{l}\text { mean energy dissipation rate per unit } \\
\text { mass }\left[\mathrm{J} \mathrm{kg}^{-1} \mathrm{~s}^{-1}\right]\end{array}$ \\
\hline & diameter of the largest drop $[\mu \mathrm{m}]$ & $\phi$ & volume fraction of the dispersed phase \\
\hline & cumulative distribution by number [\%] & & \\
\hline & $\begin{array}{l}\text { frequency distribution by number }[\%] \\
\text { cumulative distribution by volume }[\%]\end{array}$ & $\phi_{s}$ & $\begin{array}{l}\text { volume fraction of the emulsion's satel- } \\
\text { lite drops [-] }\end{array}$ \\
\hline & frequency distribution by volume [\%] & $\rho_{c}$ & density of the continuous phase \\
\hline & of the daughter drop distribution [\%] & $\rho_{d}$ & density of the dispersed phase $\left[\mathrm{kg} \mathrm{m}^{-3}\right]$ \\
\hline$f_{v, s}$ & $\begin{array}{l}\text { fitted frequency distribution by volume } \\
\text { of the satellite drop distribution [\%] }\end{array}$ & $\begin{array}{l}\sigma \\
\tau\end{array}$ & $\begin{array}{l}\text { interfacial tension }\left[\mathrm{N} \mathrm{m}^{-1}\right] \\
\text { stress }[\mathrm{Pa}]\end{array}$ \\
\hline & $\begin{array}{l}\text { fitted frequency distribution by volume } \\
\text { of the whole distribution [\%] }\end{array}$ & \multicolumn{2}{|c|}{ Dimensionless numbers } \\
\hline \multirow{3}{*}{$\begin{array}{l}M A E \\
M o_{d} \\
M o_{s} \\
N\end{array}$} & $\begin{array}{l}\text { Or the whole distribution [\%] } \\
\text { mean absolute error [\%] }\end{array}$ & Po & Power number. Po $=P \rho^{-1} N^{-2} D^{-5}$ \\
\hline & mode of the daughter drops $[\mu \mathrm{m}]$ & $\operatorname{Re}$ & Reynolds number. $\operatorname{Re}=\rho_{c} N D^{2} \mu_{c}^{-1}$ \\
\hline & $\begin{array}{l}\text { mode of the satellite drops }[\mu \mathrm{m}] \\
\text { impeller speed }\left[\mathrm{s}^{-1}\right]\end{array}$ & $\mathrm{Vi}_{\mathrm{C}}$ & $\begin{array}{l}\text { Calabrese's viscosity group Vi }= \\
\mu_{d} N D\left(\rho_{c} / \rho_{d}\right)^{1 / 2} \sigma^{-1}\end{array}$ \\
\hline \multirow{2}{*}{$\begin{array}{l}n_{r i} \\
P \\
p\left(d_{i}\right)\end{array}$} & $\begin{array}{l}\text { refractive index }[-] \\
\text { power }[\mathrm{W}]\end{array}$ & $\mathrm{Vi}_{\mathrm{H}}$ & $\begin{array}{l}\text { Hinze's viscosity group } \text { Vi }= \\
\mu_{d} \rho_{d}^{-1} \sigma^{-1} d_{\max }^{-1}\end{array}$ \\
\hline & $\begin{array}{l}\text { probability density of the drop class } i \\
{\left[\mathrm{~m}^{-1}\right]}\end{array}$ & $W_{\text {crit }}$ & $\begin{array}{l}\text { critical Weber number for drop } \\
\text { breakup. }\end{array}$ \\
\hline & coefficient of determination $[-]$ & $\mathrm{We}_{\mathrm{d}}$ & Weber number of the droplet $\mathrm{We}_{\mathrm{d}}=$ \\
\hline & $\begin{array}{l}\text { standard deviation of } \log \left(d_{i} / M o_{d}\right) \text { of } \\
\text { the daughter drops [-] }\end{array}$ & $\mathrm{We}_{\mathrm{S}}$ & $\begin{array}{l}\tau d_{\max } \sigma^{-1} \\
\text { Weber number of the stirrer } \mathrm{We}_{\mathrm{S}}=\end{array}$ \\
\hline & $\begin{array}{l}\text { standard deviation of } \log \left(d_{i} / M o_{d}\right) \text { of } \\
\text { the satellite drops [-] }\end{array}$ & & $\rho_{c} N^{2} D^{3} \sigma^{-1}$ \\
\hline & diameter of the tank $[\mathrm{m}]$ & \multicolumn{2}{|c|}{ Abbreviations } \\
\hline & Volume of the vessel $\left[\mathrm{m}^{3}\right]$ & $\begin{array}{l}\text { DSD } \\
\text { SiOil }\end{array}$ & $\begin{array}{l}\text { droplet size distribution } \\
\text { silicon oil }\end{array}$ \\
\hline \multicolumn{2}{|c|}{ Greek symbols } & SLES & sodium laureth sulfate \\
\hline
\end{tabular}

2. Hinze, J.O.. Fundamentals of the hydrodynamic mechanism of splitting in dispersion processes. AIChE Journal 1955;1(3):289-295. doi: 10.1002/aic.690010303. 
3. Kolmogorov, A.. The local structure of turbulence in incompressible viscous fluid for very large reynolds numbers. Comptes Rendus De $L$ Academie Des Sciences De L URSS 1941;30:301-305.

4. Zhou, G., Kresta, S.M.. Correlation of mean drop size and minimum drop size with the turbulence energy dissipation and the flow in an agitated tank. Chemical Engineering Science 1998;53(11):2063-2079. doi:10.1016/S0009-2509(97)00438-7.

5. Gabriele, A., Nienow, A., Simmons, M.. Use of angle resolved piv to estimate local specific energy dissipation rates for up- and downpumping pitched blade agitators in a stirred tank. Chemical Engineering Science 2009;64(1):126-143. doi:10.1016/j.ces.2008.09.018.

6. Rushton, J., Costrich, E., Everett, H.. Power characteristics of mixing impellers .1. Chemical Engineering Progress 1950;46(8):395-404.

7. Shinnar, R., Church, J.M.. Statistical theories of turbulence in predicting particle size in agitated dispersions. Industrial $\&$ Engineering Chemistry 1960;52(3):253-256. doi:10.1021/ie50603a036.

8. Sprow, F.. Distribution of drop sizes produced in turbulent liquidliquid dispersion. Chemical Engineering Science 1967;22(3):435-442. doi:doi.org/10.1016/0009-2509(67)80130-1.

9. Nishikawa, M., Mori, F., Kayama, T., Nishioka, S.. Drop size distribution in a liquid-liquid phase mixing vessel. Journal of Chemical Engineering of Japan 1991;24(1):88-94. doi:10.1252/jcej.24.88. 
10. Calabrese, R.V., Chang, T.P.K., Dang, P.T.. Drop breakup in turbulent stirred-tank contactors. part i: Effect of dispersed-phase viscosity. AIChE Journal 1986;32(4):657-666. doi:10.1002/aic.690320416.

11. Li, M., Liu, C., Liang, C., Liu, C., Li, J.. Study of bimodal drop size distributions of emulsion. Journal of Dispersion Science and Technology 2014;35(3):397-402. doi:10.1080/01932691.2013.791989.

12. Liu, C.W., Li, M.Z.. Effect of dispersed phase viscosity on emulsification in turbulence flow. Applied Mechanics and Materials 2013;446447:571-575. doi:10.4028/www.scientific.net/AMM.446-447.571.

13. Singh, K., Mahajani, S., Shenoy, K., Ghosh, S.. Representative drop sizes and drop size distributions in a/o dispersions in continuous flow stirred tank. Hydrometallurgy 2008;90(2-4):121-136. doi: 10.1016/j.hydromet.2007.10.003.

14. Wang, C.Y., Calabrese, R.V.. Drop breakup in turbulent stirred-tank contactors. part ii: Relative influence of viscosity and interfacial tension. AIChE Journal 1986;32(4):667-676. doi:10.1002/aic.690320417.

15. Calabrese, R.V., Wang, C.Y., Bryner, N.P.. Drop breakup in turbulent stirred-tank contactors. part iii: Correlations for mean size and drop size distribution. AIChE Journal 1986;32(4):677-681. doi: 10.1002/aic.690320418.

16. Arai, K., Konno, M., Matunaga, Y., Saito, S.. Effect of dispersedphase viscosity on the maximum stable drop size for breakup in turbu- 
lent flow. Journal of Chemical Engineering of Japan 1977;10(4):325-330. doi:10.1252/jcej.10.325.

17. Noro, S.. Studies on liquid-liquid dispersion by mechanical agitation. Progress in Organic Coatings 1978;6(3):271-314. doi:10.1016/03009440(78)80007-1.

18. Vankova, N., Tcholakova, S., Denkov, N.D., Ivanov, I.B., Vulchev, V.D., Danner, T.. Emulsification in turbulent flow 1. mean and maximum drop diameters in inertia and viscous regimes. Journal of Colloid and Interface Science 2007;312(2):363-380. doi: 10.1016/j.jcis.2007.03.059.

19. Boxall, J.A., Koh, C.A., Sloan, E.D., Sum, A.K., Wu, D.T.. Drop size scaling of water-in-oil emulsions under trubulent flow. Langmuir 2012;28(1):104-110. doi:10.1021/la202293t.

20. Qi, L., Meng, X., Zhang, R., Liu, H., Xu, C., Liu, Z., Klusener, P.A.. Droplet size distribution and droplet size correlation of chloroaluminate ionic liquid-heptane dispersion in a stirred vessel. Chemical Engineering Journal 2015;268:116-124. doi:10.1016/j.cej.2015.01.009.

21. Liu, C., Li, M., Liang, C., Wang, W.. Measurement and analysis of bimodal drop size distribution in a rotor-stator homogenizer. Chemical Engineering Science 2013;102:622-631. doi:10.1016/j.ces.2013.08.030.

22. Kraume, M., Gbler, A., Schulze, K.. Influence of physical properties on drop size distribution of stirred liquid-liquid disper- 
sions. Chemical Engineering and Technology 2004;27(3):330-334. doi: 10.1002/ceat.200402006.

23. Pacek, A., Man, C., Nienow, A.. On the sauter mean diameter and size distributions in turbulent liquid/liquid dispersions in a stirred vessel. Chemical Engineering Science 1998;53(11):2005-2011. doi:10.1016/S0009-2509(98)00068-2.

24. Chen, H.T., Middleman, S.. Drop size distribution in agitated liquid-liquid systems. AIChE Journal 1967;13(5):989-995. doi: 10.1002/aic.690130529.

25. Brown, D., Pitt, K.. Drop size distribution of stirred non-coalescing liquid-liquid system. Chemical Engineering Science 1972;27(3):577-583. doi:10.1016/0009-2509(72)87013-1.

26. Hall, S., Cooke, M., El-Hamouz, A., Kowalski, A.. Droplet break-up by in-line silverson rotor-stator mixer. Chemical Engineering Science 2011;66(10):2068-2079. doi:doi:10.1016/j.ces.2011.01.054.

27. Carrillo De Hert, S., Rodgers, T.L.. On the effect of dispersed phase viscosity and mean residence time on the droplet size distribution for high-shear mixers. Chemical Engineering Science 2017;172:423 - 433.

28. Laso, M., Steiner, L., Hartland, S.. Dynamic simulation of agitated liquid-liquid dispersions-ii. experimental determination of breakage and coalescence rates in a stirred tank. Chemical Engineering Science 1987;42(10):2437-2445. doi:10.1016/0009-2509(87)80117-3. 
29. Chatzi, E.G., Costas, J.B., Costas, K.. On-line monitoring of drop size distributions in agitated vessels. 2. effect of stabilizer concentration. Industrial and Engineering Chemistry Research 1991;30:1307-1313. doi: 10.1021/ie00054a035.

30. Groeneweg, F., van Dieren, F., Agterof, W.. Droplet break-up in a stirred water-in-oil emulsion in the presence of emulsifiers. Colloids and Surfaces A: Physicochemical and Engineering Aspects 1994;91:207-214. doi:10.1016/0927-7757(94)02913-X.

31. Zhou, G., Kresta, S.M.. Evolution of drop size distribution in liquidliquid dispersions for various impellers. Chemical Engineering Science 1998;53(11):2099-2113. doi:10.1016/S0009-2509(97)00437-5.

32. El-Hamouz, A.. Effect of surfactant concentration and operating temperature on the drop size distribution of silicon oil water dispersion. Journal of Dispersion Science and Technology 2007;28(5):797-804. doi: 10.1080/01932690701345893.

33. Eastwood, C., Armi, L., Lasheras, J.. The breakup of immiscible fluids in turbulent flows. Journal of Fluid Mechanics 2004;502:309-333. doi:10.1017/S0022112003007730.

34. Andersson, R., Andersson, B.. On the breakup of fluid particles in turbulent flows. AIChE Journal 2006;52(6):2020-2030. doi: 10.1002/aic.10831.

35. Nachtigall, S., Zedel, D., Kraume, M.. Analysis of drop deformation dynamics in turbulent flow. Chi- 
549

550

551

552

553

554

555

556

557

nese Journal of Chemical Engineering 2016;24(2):264 277. doi:https://doi.org/10.1016/j.cjche.2015.06.003. URL http://www. sciencedirect. com/science/article/pii/S1004954115002098.

36. Solsvik, J., Maa, S., Jakobsen, H.A.. Definition of the single drop breakup event. Industrial and Engineering Chemistry Research 2016;55(10):2872-2882.

37. Davies, J.T.. Drop sizes of emulsions related to turbulent energydissipation rates. Chemical Engineering Science 1985;40(5):839-842. doi:10.1016/0009-2509(85)85036-3. 